\title{
Is India Ready for e-Mobility? An Exploratory Study to Understand e-Vehicles Purchase Intention
}

\author{
Sita Mishra, Gunjan Malhotra \\ Institute of Management Technology, Ghaziabad, India \\ Email:smishra@imt.edu
}

How to cite this paper: Mishra, S. and Malhotra, G. (2019) Is India Ready for e-Mobility? An Exploratory Study to Understand e-Vehicles Purchase Intention. Theoretical Economics Letters, 9, 376-391. https://doi.org/10.4236/tel.2019.92027

Received: December 11, 2018

Accepted: February 23, 2019

Published: February 26, 2019

Copyright () 2019 by author(s) and Scientific Research Publishing Inc. This work is licensed under the Creative Commons Attribution International License (CC BY 4.0).

http://creativecommons.org/licenses/by/4.0/

(c) (i) Open Access

\begin{abstract}
Most of the urban Indian cities face challenges of traffic congestion and severe air pollution due to rapid urbanization and growth in automobiles. As a result, there is a potential need for adopting alternative technologies in automobiles such as electric vehicles (EV). The focus of this study is to explore various influencers of purchase intention of EVs in India by proposing a framework based on utility theory that integrates economic and psychological perspectives. Data for this study was collected from a sample of 228 respondents using the mall intercept method in India. This study used confirmatory factor analysis in AMOS version 25 to examine the role of performance features, financial benefits, environmental concerns, social influence, cost of ownership and infrastructure support on purchase intention of Indian consumers towards EVs. The study revealed environmental concern and performance features as most important factors influencing Indian consumers' consumption behavior towards EVs. Presently, two factors-cost of ownership and infrastructure support were not imperative for the adoption of Evs to Indians. As environmental concern was the most important factor for Indian consumers, therefore, it is pertinent for car manufacturers and policymaker to highlight the environmental benefits of e-Mobility.
\end{abstract}

\section{Keywords}

Automobile Sector, Electric Vehicle, Utility Theory, Purchase Intention, India, e-Mobility

\section{Introduction}

Due to rapid urbanization and growth in automobiles, most of the urban Indian cities are not only experiencing increased traffic congestion but also confronted with severe air pollution. Transportation contributes for more than 10 percent of 
India's carbon emissions and is a most challenging factor in curbing air pollution in several urban cities. Air pollution is a major concern area for India, as 14 of the world's top 20 most-polluted cities are in India, according to a 2018 World Health Organization report (mentioned in Centre for Science and Environment) [1]. Increase in carbon emission has an immense influence on climate change and air quality. Additionally, it creates health related problems and also contributes to tremendous economic loss because of a surge in financial resources required for medical assistance to the affected people. In India, crude oil imports contribute significantly and are responsible for the current account deficit [2].

To combat this pollution problem, across the globe countries are making efforts to regulate carbon emissions. The global automotive industry is expecting to play a crucial role in the next few years and will work towards new technological trend viz. electric, shared, connected and autonomous driving. Additionally, to create momentum and augment adoption of e-Mobilty, governments are working towards lowering battery cost, provide a better total cost of ownership and enhancing infrastructure support [3]. McKinsey report [2] expressed Emobility as "a new concept is gaining attention across the world as a promising solution to this problem and substantially improve environmental efficiency." In this current research, e-Mobility denotes vehicular movement that depends on plug-in electricity as their prime source of energy and includes all categories of electric vehicles (EVs) such as Battery Electric Vehicles, Plug-in Hybrid Electric Vehicles (PHEV) and Extended Range Electric Vehicles(EREV). The e-Mobility is applicable for four-wheelers, power-two-wheelers, vans and, quadricycles.

At present, globally transportation is using Internal combustion engine (ICE) (running on CNG, Petrol or Diesel) but it is expected to start declining in the mid-2020s. However, the pace of adoption of e-Mobility may vary from country. According to Bloomberg New Energy Finance forecasts, by 2030 EVs will gain popularity in European and Chinese market with $44 \%$ and $41 \%$ of sales respectively, followed by $34 \%$ in the US, and $17 \%$ in Japan as per FE Bureau [4]. Nevertheless, due to a shortage of charging infrastructure and a lack of affordable models the sales of EVs s expected to be just 7\% of new car sales by 2030. Electric vehicles (EVs) emerge as a way forward to combat challenges like climate change, the increase in oil prices and long-term oil scarcity. As per a NITI Aayog report, India can conservatively save 64 percent of anticipated passenger mobility-relate energy demand and 37 percent of carbon emissions by 2030 by focusing on the new concept of shared, electric and connected e-Mobility [5]. The Indian government also promoted the National Electric Mobility Mission Plan (NEMMP), 2020 for achieving national fuel security by promoting hybrid and electric vehicles. The Indian government focuses on EVs and targets only electric vehicles to ply on India's roads by 2030 as part of its climate change commitment and to reduce spending on oil imports.

In developed economies like the US and Germany, around 30 to 45 percent of vehicle buyers already consider E-vehicles as an option while choosing a car. At 
the end of 2018, global EV sales are approx 4 million and are largely driven by China, however with the entry of many new EV models in next few months and emphasis of different push and pull factors across the world there should be a surge in global EV purchases. On the push side, the limited oil supply and the rising awareness of the environmental footprint of conventional combustion engine vehicles lead the way to cleaner EVs. While the pull factors include recent developments in battery technology and electric motors make the EVs as a useful alternative option for conventional cars. Tesla Model 3 is also expected to enter in European markets in mid-2019, which will likely increase EV sales in the region further.

The concept of E-mobility is a nascent concept in India. At the moment there are only electric, and hybrid vehicles are available for sale, plug-in hybrids are yet to arrive at the market. The attitude and behavior of consumers towards E-vehicles are yet to explore in India. In this background of the global focus on eMobility and Indian government policy for promotion of EVs, it is imperative to explore factors influencing Indian consumers to purchase intention towards EV. The current study examines Indians consumer behavior towards EVs in comparison to ICE based vehicles and proposes a testable framework of consumer purchase intention based on utility theory. The purpose of this paper is to explore the role of performance features, financial benefits, environmental concerns, social influence, cost of ownership and infrastructure support on purchase intention of Indian consumers towards EVs. The study focuses on exploring purchase intentions in the context of utility theory by amalgamating economic and psychological perspectives and associating these factors with key marketing influencers of buying decision of EVs. The reason for using utility theory in consumer economics is due to the assumption that consumers make choices based on the expected outcomes of their decisions and maximizes the utility rationally. In the past, several researchers studied utility theory by assimilating the economic and psychological aspects of consumers [6] [7]. Consumers will not adopt EVs unless they find performance and financial benefits, adequate infrastructure support and cost of ownership. This research is essential in the current market condition of India, as there is a huge push from government to adopt EVs and there is a lack of recent studies on this topic in India, which entails a gap in the scientific literature.

The paper is organized as follows: in the first part it explains purchase intention in the context of utility theory and provides a relevant literature review for the theoretical framework and hypothesis development. The next section describes the research methodology and measurement. The following section presents the main findings of the study. The last section describes discussion and conclusion along with limitations and implications for marketers and policymakers.

\section{Literature Review}

\subsection{Theoretical Framework}

This section discusses purchase intention in context of utility and the impact of 
six prominent factors on purchase intention viz. performance features, financial benefits, environmental concerns, social influence, cost of ownership and infrastructure support (as depicted in Figure 1).

\subsection{Purchase Intention in the Context of Utility Theory}

Utility theory is one of the widely accepted theories of consumer behavior that explains why people perform objectively rational behavior and how they maximize the expected utility for personal benefit to achieve satisfaction [8]. Thus, consumers will think about the choices to the preferences and maximize the utility rationally. However, in the context of consumer decision making this economic perspective may not be sufficient enough to explain consumption behavior regarding selection between two or more alternatives. As pointed out by researchers, consumer's decision is based upon a set of motives and alternative chains of action [9], psychological factors [10] and learning history comprising by personal factors and state variables [11]. Hauser and Urban [12] described utility function through physical cues and psychological attributes. Thus, consumers may choose alternatives to enhance expectations; their decision making may depend on perceived utility, benefits, or perceived value of the offering. Several psychological and social factors may influence consumers. Also their past experiences might influence their behavior, thinking and emotions, thus obtain higher value by product benefit in their future purchase intentions. In the context of utility theory, purchase intention is influenced by consumers purchase decision based on various alternatives to enhance expectations within a given set of risks and benefits.

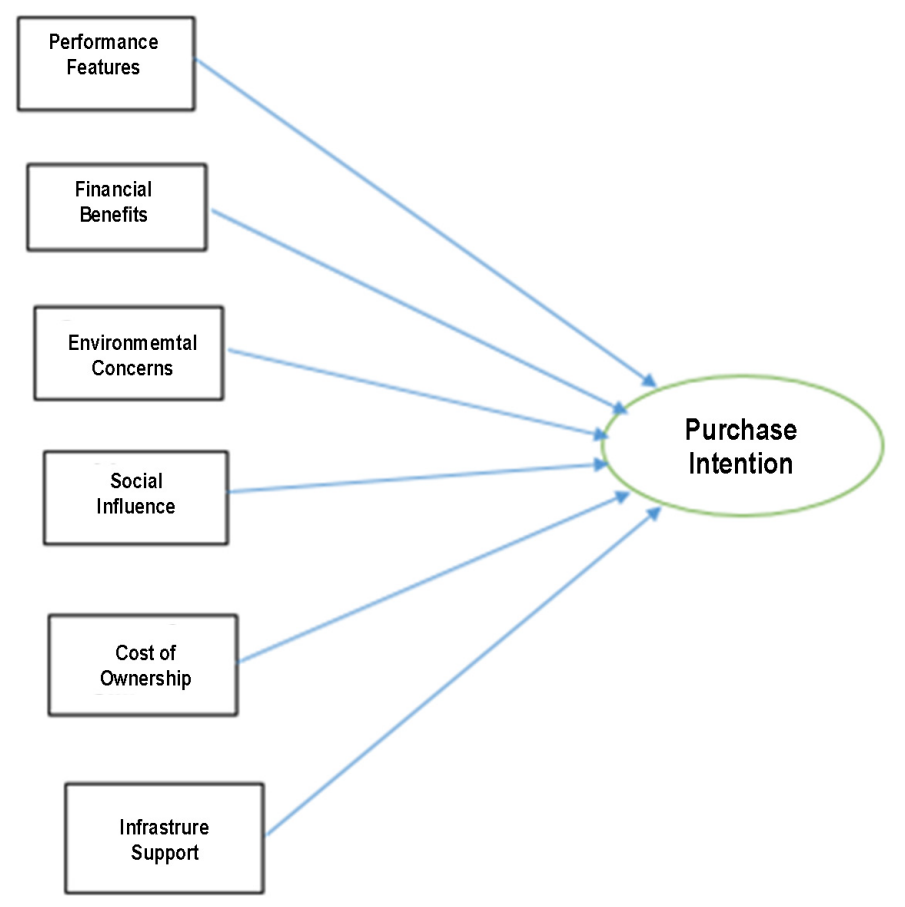

Figure 1. Proposed Framework of the study. Source: Designed by authors. 


\subsection{Performance Features (PF)}

Past studies indicated customers concern for the longest range that EVs can drive in one charge [13] [14], charging time [15], safety and reliability [16]. Ozaki \& Sevastyanova [17] carried out a study of consumer adoption of hybrid vehicles and investigated the dimensions that constitute motivations to purchase the Prius. They found that performance considerations such as comfort, quietness, ease of driving, automatic transmission and convenience of use are among the vital factors influencing consumer adoption.

Similarly, in a study among Chinese consumers, performance features viz. riding comfort, safety, the convenience of use, and operability, were found to have an impact on the acceptance of a new energy vehicle [18]. The consumer tends to adopt new technology (such as EVs) when they see the higher performance of EVs compared with conventional vehicles [15]. Past studies also suggested that limited traveling range [19] and long recharging time [20] as shortcomings for consumers' adoption towards EVs. Achtnicht [21] investigated German consumers' behavior and found that the majority of the respondents preferred more horsepower when making a purchasing decision. On the basis of literature review, it is hypothesized that

H1: Performance features have a significant and positive relationship with purchase intention for E-vehicles.

\subsection{Financial Advantages (FA)}

Past researchers indicated consumers interest for EVs due to financial gains, and as a result, they show an inclination towards adopting greener vehicles which could lessen the operational cost of running vehicles and increase the fuel efficiency [22]. Chanaron and Teske [23] described the rising fuel price as a critical factor considered by people. Consumers may be willing to adopt EVs depending upon receiving direct financial benefits, conveniences or habits or indirect advantages such as lower fuel cost, reduced energy consumption and lower maintenance cost [24]. However, the benefit from investing in EVs may be limited if car buyers only use their EVs for a short distance [13]. Also, researchers considered the resale price of EVs [16] [25] as another financial factor influencing purchase and found that consumers may have resale anxiety because the secondary market for EVs is still unpredictable. Thus, it is hypothesized that

$\mathrm{H} 2$ : Financial advantages have a significant and positive relationship with purchase intention for E-vehicles.

\subsection{Environmental Concern (EC)}

Environmental concern is considered as a degree of people's knowledge and awareness towards environmental consciousness and support they are ready to provide to preserve the environment and solve problems regarding the environment. Past studies indicated that consumers with stronger concern towards environment or who identify themselves as an environmentally-friendly person 
or who display pro-environmental behavior are more likely to adopt EVs [26] [27]. Additionally, sensitivity to climate change issues and energy conservation constitutes explicit dimensions of environmental concerns [28]. Past literature also indicates environmental concern's direct and indirect effects on consumers' willingness to procure green products at a premium price [29]. Gallagher and Muehlegger [30] in their study with US consumers found that groups with strong preferences for environmentalism and energy security prefer hybrid electric vehicles due to people's concern about rising gasoline prices and certain social preferences. Also, prior studies on new vehicle technologies have attempted to recognize how environmental benefits may affect customer decisions [31]. Erdem et al. [32] studied the willingness to adopt energy-efficient cars in Turkey and found that people who cared about global warming issues were likely to purchase EVs. Thus, pro-environmental behavior of consumers is linked with the adoption of new technology in vehicles. By literature review, it is hypothesized that

H3: Environmental concerns have a significant and positive relationship with purchase intention for E-vehicles.

\subsection{Social Influence (SI)}

Social Influence is defined as the extent to which an individual perceives that important others believe that they should use a particular technology. Social externalities such as peer pressure, neighborhood effect would influence the consumers to purchase EVs/PHEVs [33] [34] [35]. Interpersonal influence considered as an important influencer car buying process for "green" vehicle technology [36]. The "neighbor effect" was found to influence consumers to purchase hybrid EVs in Canada [35]. Lee [37] found peer influence as the most important predictor among Hong Kong consumers' for green purchasing behavior. Social influence is expected to influence Indian consumers as India is a collectivist society where social norms are valued, and individual actions are influenced by the group to whom one identifies himself/herself with. Therefore, in this context, it is hypothesized that

H4: Social influence has a significant and positive relationship with purchase intention for E-vehicles.

\subsection{Cost of Ownership (CO)}

The price of EVs are considered to be higher than conventional vehicles due to the high cost of electric-power train and Li-ion battery, and this high initial cost could be a deterrent for EV adoption [38]. The cost of ownership (e.g., high purchase cost, inconvenience due to limited charging infrastructure, and uncertainty about running-costs) of an $\mathrm{EV}$ is one of the financial factors that can affect the intention to buy EVs [39]. Chanaron and Teske [23] postulated rising fuel price as a major contributor for calculating the cost of car ownership. Ernst et al. [40] introduced a total cost of ownership model for the average car user in Ger- 
many to compare the energy consumption of a conventional vehicle versus a plug-in hybrid electric vehicle]. Past studies found that electric vehicles might be cheaper or more expensive than combustion engine vehicles depending on assumptions [41] [42]. Bockarjova and Steg [43] claimed the most important barriers for electric vehicle adoption were perceived high monetary and non-monetary costs of electric vehicles and benefits associated with the use of a conventional vehicle. Liu and Santos [44] had similar findings in China that when deciding whether to buy a hybrid electric vehicle, a consumer will consider the cost of the vehicle and the cost of operations. In the context of E-vehicles, it is hypothesized that

H5: Cost of ownership has a significant and negative relationship with purchase intention for E-vehicles.

\subsection{Infrastructure Support (IS)}

Infrastructure support is one of the major decision-making processes of whether or not to buy a vehicle running on a new fuel type. Past studies [45] [46] indicated factors affecting consumer adoption are charging infrastructure, the frequency of electric refueling stations. Nayum et al. [47] described that conventional car users tend to focus more on the convenience factor viz. the availability of EV charging stations within their living or working areas. Regarding the charging conditions, many studies suggested that people would adopt EVs if there were charging facilities at work [48], at home [49] and on the highways [50]. Infrastructure preparedness and support are expected to be a crucial factor to promote private adoption of EVs [16] [39]. The lack of supporting infrastructure may hinder consumer acceptance of fully electric vehicles. Therefore, it is hypothesized that

H6: Infrastructure support has a significant and positive relationship with purchase intention for E-vehicles.

\section{Methodology and Measurement}

\subsection{Data Collection}

Data for this study was collected using the mall intercept method in Delhi and NCR (National capital region) in India. Interviewers were given instructions to approach every fifth buyer to take part in a self-administered questionnaire. A total of 325 questionnaires were administered. To work with valid data, checking for outliers and suspicious response patterns was done using a multivariate outlier-analysis and some responses were dropped. Further, the study excluded few cases which were incomplete. Finally, the data analysis was done with a sample of 228 respondents.

\subsection{Demographic Characteristics}

Of the total 228 respondents, 76 percent were males, and the remaining 24 percent were females. The respondents in the age group of 18 to 30 years, 31 years 
to 40 years and more than 40 years were 16 percent, 58 percent, and 26 percent respectively. 41 percent of respondents were having Post-graduation or higher qualification, while 52 percent of them were graduates and remaining 7 percent were holding other degrees. Around 21 percent of the sample reported their average monthly household income as US $\$ 6000$ and above, while 23 percent and 27 percent had average monthly household income between US $\$ 4000$ and US $\$ 6000$ and the US $\$ 1500$ and US $\$ 4000$ respectively. Remaining respondents stated their average monthly household income less than US $\$ 1500$.

\subsection{Scale Development}

The study attempted to explore Indian consumers' intention to purchase EVs. The questionnaire was divided into two parts. In first section items related to various factors influencing the purchase intention of EVs were given while the second section focused on the demographic information of respondents. The study adopted the existing scales to develop the instrument.

Items relating to Performance features items adopted from Hidrue et al. [51] and She et al. [52]. Financial advantages items were taken from Egbue \& Long [15] and She et al., [52]. Environmental concerns scale items were derived from Razak et al. [53] and Barbarossa et al. [26]. Social influence was measured using scale items from Axsen \& Kurani [36]. Cost of ownership items was adopted from Delang \& Cheng [39] whereas Infrastructure support items were taken from Krupa et al. [54] and She et al. [52]. Purchase intention was measured using scale adapted from Hidrue et al. [51] and Wang et al. [55]. All items were measured using a five-point Likert-type response format, with "strongly disagree" and "strongly agree" as anchors.

\section{Results}

\subsection{Measurement Model, Reliability and Validity}

The data was analyzed in two stages-firstly using confirmatory factor analysis (CFA) which was performed to find a better model for the measurement of each latent variable. Secondly, structural equation modeling (SEM) was used to test the proposed hypotheses. Further, normality and reliability testing were conducted. The mean value, standard deviation, and skewness tests were used to check the normality of the data. The convergent validity of the measurement model was tested by assessing the statistical significance of the AVE and construct reliability (CR) according to Hair et al. [56], and Cronbach's alpha was used to calculate the reliability statistics.

In this study, the Cronbach's $\alpha$ values for all the measures were above 0.7 which means that the items in various constructs have relatively high internal consistency. Further, AVE for all constructs was greater than 0.5 therefore convergent validity was established which means that constructs that are expected to be related are, in fact, related. In the study, CR values for all measures were above 0.7 (which explains the reliability and internal consistency of the meas- 
ured variables representing a latent construct). Therefore, it can be concluded that Convergent Validity (AVE $\geq 0.5$ ), Internal Reliability (Cronbach Alpha $\geq$ $0.7)$ and Construct Reliability (CR $\geq 0.60)$ of all constructs had been achieved as suggested by Hair et al. [56].

\subsection{Structural Model Test}

The present study applied structural equation modeling using AMOS version 25 to test the hypothesized relationships. The analysis indicated an excellent model fit (Table 1). In this research study, the model provides a good fit to the data with a Chi-square $\left(\chi^{2}\right)=632.5$, d.f. $=276, p=0.000(p<0.05) . \chi^{2} /$ d.f. $=2.291$, Tucker-Lewis index (TLI) $=0.917$, comparative fit index $(\mathrm{CFI})=0.942$, incremental fit indices (IFI) $=0.911$ and root mean square error of approximation $($ RMSEA $)=0.025$ (Table 1$)$. All the values were within the acceptable range as recommended by Hair et al. (2010). As reflected in Table 1, overall fit statistics of the measurement model for all seven latent constructs was within the acceptable range as per Fornell and Larcker [57] (1981) and Hair et al. (2010).

As seen in Table 2 Performance features (PA), and environmental concern (EC) showed positive and significant relationship with purchase intention $(\beta=$ $0.302, \mathrm{p}<0.01 ; \beta=0.446, \mathrm{p}<0.01)$. This means performance features of EVs may influence consumers' buying intention which supports our hypothesis $\mathrm{H} 1$. Similarly, consumers' concern for the environment seems to be another important factor influencing purchase intention. Thus $\mathrm{H} 3$ was also accepted. This indicated a pro-environmental attitude of Indian consumers. Thus, consumers may prefer to buy EVs if they get better technical features and higher benefits related to environmental safety. However, relationship of financial advantages and social influence with purchase intention was positive but non-significant ( $\beta$ $=0.076, \mathrm{p}=0.305 ; \beta=0.039, \mathrm{p}=0.217)$. Thus, association of financial benefits and social influence were positive with purchase intention (which means increasing the financial benefits and social influence will increase consumers' purchase intention), but presently these factors are not important for buying

Table 1. Descriptive statistics, Reliability and Validity Composition, AVE.

\begin{tabular}{|c|c|c|c|c|c|c|}
\hline Constructs & Mean & $\begin{array}{l}\text { Standard } \\
\text { Deviation }\end{array}$ & Skewness & Cronbach $\alpha$ & CR & AVE \\
\hline Performance Feature (PA) & 4.52 & 0.692 & -1.853 & 0.782 & 0.798 & 0.543 \\
\hline Financial Advantages(FA) & 4.18 & 0.926 & -1.191 & 0.852 & 0.858 & 0.519 \\
\hline Environmental Concerns (EC) & 4.21 & 0.676 & -0.481 & 0.883 & 0.732 & 0.513 \\
\hline Social Influence (SI) & 3.48 & 0.987 & -0.490 & 0.895 & 0.892 & 0.603 \\
\hline Cost of Ownership (CO) & 3.21 & 0.883 & -0.468 & 0.712 & 0.739 & 0.565 \\
\hline Infrastructure Support (IS) & 4.49 & 0.693 & -1.362 & 0.765 & 0.807 & 0.614 \\
\hline Purchase Intention (PI) & 3.81 & 0.705 & --0.213 & 0.854 & 0.827 & 0.574 \\
\hline Fit measures & & & & \multicolumn{3}{|c|}{$\begin{array}{c}\text { Normed } \chi^{2} / \text { d.f. }=2.291, \text { CFI }= \\
0.942, \text { IFI }=0.911, \text { TLI }=0.917 \\
\text { and RMSEA }=0.025\end{array}$} \\
\hline
\end{tabular}


Table 2. Structural results.

\begin{tabular}{cccc}
\hline Path & Hypothesis & Estimate & Result \\
\hline Performance features $\rightarrow$ PI & H1 & $0.302^{* *}$ & Supported \\
Financial advantages $\rightarrow$ PI & H2 & 0.076 & $\begin{array}{c}\text { Partially } \\
\text { Supported } \\
\text { Environmental concerns } \rightarrow \text { PI }\end{array}$ \\
Social influence $\rightarrow$ PI & H3 & $0.446^{* *}$ & Supported \\
Cost of ownership $\rightarrow$ PI & H4 & 0.039 & Supported \\
Infrastructure support $\rightarrow$ PI & H5 & $0.107^{\text {ns }}$ & Rejected \\
\hline
\end{tabular}

${ }^{*}$ significant at $\mathrm{p}<0.01$, non-significant $(\mathrm{ns})$ as $\mathrm{p}>0.05$.

EVs. Therefore, $\mathrm{H} 2$ and $\mathrm{H} 4$ were partially supported (due to the direction of association of these two factors-financial advantages and social influence was positive, but these were non-significant).

Further, Infrastructure support was negative and non-significant $\beta=(-) 0.10$. This means Indian consumers might not consider infrastructure support required for buying EVs. Presently, they indicated readiness to buy EVs even if required infrastructure support is not present. Thus, the lack of infrastructure will not hinder their purchase intention. Finally, the cost of ownership (CO) showed a positive and non-significant relationship with purchase intention $(\beta=$ 0.107). This means Indians are interested in buying EVs even if the associated cost of the vehicle is high which was against our hypothesis H5. Thus, both H5 and $\mathrm{H} 6$ were rejected.

\section{Discussion and Conclusions}

This study is conducted to explore various factors that influence Indian consumers to intend to buy electric vehicles (EVs). So far, no study has been carried out to understand consumption behaviors of Indian consumers towards e-mobility. The study applied utility theory through the integration of economic and psychological perspectives by proposing a valuable framework to understand the key influencers of consumer behavior in the context of EVs. Based on past studies, the current study identified six key factors that may influence consumer behavior for EVs: a) Performance features, b) Financial advantages, c) Environmental concerns, d) Social influence, e) Cost of ownership, and f) Infrastructure support.

Findings of the current study indicated a positive association of performance features and purchase intention for EVs. This finding of the study is in line with past studies [13] [32] [47] that support the presence of performance attributes to determine the intention to buy EVs. Though, presently availability of EVs is in nascent stage still people believe that these EVs may provide a lot of technical and superior features in comparison to conventional ICE based vehicles. Thus, to promote EVs in the Indian market, car manufacturers should highlight performance factors as their unique selling points. To educate Indian buyers, mar- 
keters can also showcase how EVs can outperform conventional vehicles, as people may lack an understanding of the performance difference between EVs and Internal combustion based vehicles.

Further, the study indicated a significant and positive association of purchase intention with environmental concern. Surprisingly, environment concern appears to be the most important influencer of consumers' buying intention. This finding matches with previous researches that highlighted that environmental concerns are an initial factor that stimulates the need for EVs and influence attitude towards EV adoption [26] [58].

Therefore, it is relevant for car manufacturers and policymaker to highlight the environmental benefits of e-Mobility and exhibit how EVs could play a part in combating air pollution. This enhanced knowledge might encourage consumers to take action towards EVs. Respondents seem to believe that environmental issues are of vital importance to secure a better quality of life, and are ready to change and adopt new technologies which support individual mobility while minimizing $\mathrm{CO} 2$ emissions. Consumers' knowledge on the issue of climate change and energy efficiency would help to impact the level of acceptance of EVs. Automobile manufacturers could also provide information on the labeling system highlighting the environmental efficiency of the vehicles.

The study indicated the positive and non-significant relationship of cost of ownership with purchase intention. Indians generally are price conscious, but it seems that they are ready to spend on EVs. This may be either they are too concern for the environment or too enthusiastic about new technology. Marketers are required to study more insights about Indian consumers on charging price premiums as their interest in purchase intention may be due to less knowledge about the cost associated with EVs. This finding is in line with other studies [51] [59].

Financial advantages and social influences were positively associated with purchase intention (as hypothesized), but both factors were non-significant. Further, infrastructure support was negatively associated with purchase intention and non-significant. Thus, it seems at present no influence of these factors on consumers' acceptance for EVs. This is in contrast with previous studies [52] [60] which indicated the importance of financial benefits and infrastructure support. Though, these findings are in line with Thananusak et al. study in Thailand wherein infrastructure and financial performances were not important influencers for consumers. This may be because people might think that by the time EVs enter in the market, they'll get adequate infrastructure. Whereas, in reality, the lack of infrastructure support may hinder consumers' intention to purchase EVs. In India, EVs are in the nascent stage, as a result people are not able to perceive the financial benefits that these vehicles can provide. The introduction of EVs requires critical government role and implementation policies as the Indian government could play a leading role in changing adoption to full EVs by offering tax incentives for purchasing light environmentally friendly vehicles and establishing the supporting infrastructure for EVs, such as providing 
free public charging stations as well as toll-free roads. Despite India being a collectivist society, social influence does not seem to influence people's consumption behavior toward EVs.

The study has several limitations which provide possible directions for future scope of this research. Firstly, the study explored the influence of six factors on the intention to buy EVs. Thus, it only provides a fragment of the consumption process towards EVs. Future study may take some more psychological, technical and interpersonal factors that might influence consumer's purchase intention to widen the scope of this research area. Secondly, there might be a gap between the intention and actual adoption behavior [48] towards EVs. Presently people have inadequate knowledge and awareness about EVs, as full EVs are still not commonly adopted in many countries. People could change their mind when they have the real driving experience with EVs [61]. Thirdly, the findings need to be further validated with larger sample size, and future studies could also focus on the impact of socio-demographic variables on purchase intention of EVs.

\section{Conflicts of Interest}

The authors declare no conflicts of interest regarding the publication of this paper.

\section{References}

[1] CSE (2018) WHO Ranking of Polluted Cities Explained, Bad News for India. https://www.cseindia.org/2018-who-ranking-of-polluted-cities-explained-bad-news -for-india-8673

[2] McKinsey Report (2017) The Future of Mobility in India: Challenges \& Opportunities for the Auto Component Industry.

https://www.mckinsey.com/industries/automotive-and-assembly/our-insights/the-f uture-of-mobility-in-india-challenges-and-opportunities-for-the-auto-component-i ndustry

[3] McKinsey \& Company (2016) Disruptive Trends That Will Transform the Auto Industry, Paul Gao, Hans-Werner Kaas, Detlev Mohr and Dominik Wee. http://www.mckinsey.com/industries/automotive-ndassembly/our-insights/disrupti ve-trends-that-will-transform-the-auto-industry

[4] Electric Vehicles Will Make up Only 7\% of New Car Sales in India in 2030. https://www.financialexpress.com/industry/electric-vehicles-will-make-up-only-7-o f-new-car-sales-in-india-in-2030/1234505/

[5] Aayog, N. (2017) India Leaps Ahead: Transformative Mobility Solutions for All. http://niti.gov.in/writereaddata/files/document_publication/RMI_India_Report_we b.pdf

[6] Johnson, M.D. and Fornell, C. (1991) A Framework for Comparing Customer Satisfaction across Individuals and Product Categories. Journal of Economic Psychology, 12, 267-286. https://doi.org/10.1016/0167-4870(91)90016-M

[7] Rabin, M. (2002) A Perspective on Psychology and Economics. European Economic Review, 46, 657-685. https://doi.org/10.1016/S0014-2921(01)00207-0

[8] Merwe, R.V.D., Berthon, P., Pitt, L. and Barnes, B. (2007) Analysing "Theory Networks": Identifying the Pivotal Theories in Marketing and Their Characteristics. 
Journal of Marketing Management, 23, 181-206. https://doi.org/10.1362/026725707X196332

[9] Howard, J.A. and Sheth, J.N. (2001) Marketing: Critical Perspectives on Business and Management. Routledge, London.

[10] Bayton, J.A. (1958) Motivation, Cognition, Learning: Basic Factors in Consumer Behavior. Journal of Marketing, 22, 282-289.

[11] Foxall, G.R. (1994) Consumer Choice as an Evolutionary Process; an Opérant Interpretation of Adopter Behavior. Advances in Consumer Research, 21, 312-317.

[12] Hauser, J.R. and Urban, G.L. (1979) Assessment of Attribute Importances and Consumer Utility Functions: Von Neumann-Morgenstern Theory Applied to Consumer Behavior. Journal of Consumer Research, 5, 251-262. https://doi.org/10.1086/208737

[13] Degirmenci, K. and Breitner, M.H. (2017) Consumer Purchase Intentions for Electric Vehicles: Is Green More Important Than Price and Range? Transportation Research Part D: Transport and Environment, 51, 250-260. https://doi.org/10.1016/j.trd.2017.01.001

[14] Lebeau, K., Mierlo, J.V., Lebeau, P., Mairesse, O. and Macharis, C. (2013) Consumer Attitudes towards Battery Electric Vehicles: A Large-Scale Survey. International Journal of Electric and Hybrid Vehicles, 5, 28. https://doi.org/10.1504/IJEHV.2013.053466

[15] Egbue, O. and Long, S. (2012) Barriers to Widespread Adoption of Electric Vehicles: An Analysis of Consumer Attitudes and Perceptions. Energy Policy, 48, 717-729. https://doi.org/10.1016/j.enpol.2012.06.009

[16] Lim, M.K., Mak, H.-Y. and Rong, Y. (2014) Toward Mass Adoption of Electric Vehicles: Impact of the Range and Resale Anxieties. Manufacturing and Service Operations Management, 17, 101-119.

[17] Ozaki, R. and Sevastyanova, K. (2011) Going Hybrid: An Analysis of Consumer Purchase Motivations. Energy Policy, 39, 2217-2227. https://doi.org/10.1016/j.enpol.2010.04.024

[18] Zhang, X., Wang, K., Hao, Y., Fan, J.-L. and Wei, Y.-M. (2013) The Impact of Government Policy on Preference for NEVs: The Evidence from China. Energy Policy, 61, 382-393. https://doi.org/10.1016/j.enpol.2013.06.114

[19] Bunch, D.S., Bradley, M., Golob, T.F., Kitamura, R. and Occhiuzzo, G.P. (1992) Demand for Clean-Fuel Personal Vehicles in California: A Discrete-Choice Stated Preference Survey. Inst. Transportation Studies, University of California, Irvine.

[20] Cheron, E. and Zins, M. (1997) Electric Vehicle Purchasing Intentions: The Concern over Battery Charge Duration. Transportation Research Part A, 31, 235-243. https://doi.org/10.1016/S0965-8564(96)00018-3

[21] Achtnicht, M. (2012) German Car Buyers' Willingness to Pay to Reduce $\mathrm{CO}_{2}$ Emissions. Climatic Change, 113, 679-697. https://doi.org/10.1007/s10584-011-0362-8

[22] Mourato, S., Saynor, B. and Hart, D. (2004) Greening London's Black Cabs: A Study of Driver's Preferences for Fuel Cell Taxis. Energy Policy, 32, 685-695. https://doi.org/10.1016/S0301-4215(02)00335-X

[23] Chanaron, J.-J. and Teske, J. (2007) Hybrid Vehicles: A Temporary Step. International Journal of Automotive Technology and Management, 7, 268-288. https://doi.org/10.1504/IJATM.2007.017061

[24] Potoglou, D. and Kanaroglou, P.S. (2007) Household Demand and Willingness to Pay for Clean Vehicles. Transportation Research Part D, 12, 264-274. 
https://doi.org/10.1016/j.trd.2007.03.001

[25] Banerjee, S. and Pillania, R.K. (2009) Relative Position of Resale Value as a Decision Variable in a Car Purchase: A Thurstone Case V Analysis of a Multiattribute Car Purchase Decision Model in India. International Journal of Electric and Hybrid Vehicles, $2,77$.

[26] Barbarossa, C., De Pelsmacker, P. and Moons, I. (2017) Personal Values, Green Self-Identity and Electric Car Adoption. Ecological Economics, 140, 190-200.

[27] Krause, R.M., Carley, S.R., Lane, B.W. and Graham, J.D. (2013) Perception and Reality: Public Knowledge of Plug-In Electric Vehicles in 21 U.S. Cities. Energy Policy, 63, 433-440. https://doi.org/10.1016/j.enpol.2013.09.018

[28] Zimmer, M.R., Stafford, T.F. and Stafford, M.R. (1994) Green Issues: Dimensions of Environmental Concern. Journal of Business Research, 30, 63-74. https://doi.org/10.1016/0148-2963(94)90069-8

[29] Laroche, M., Bergeron, J. and Barbaro-Forleo, G. (2001) Targeting Consumers Who Are Willing to Pay More for Environmentally Friendly Products. Journal of Consumer Marketing, 18, 503-520. https://doi.org/10.1108/EUM0000000006155

[30] Gallagher, K.S. and Muehlegger, E. (2011) Giving Green to Get Green? Incentives and Consumer Adoption of Hybrid Vehicle Technology. Journal of Environmental Economics and Management, 61, 1-15.

[31] Schuitema, G., Anable, J., Skippon, S. and Kinnear, N. (2013) The Role of Instrumental, Hedonic and Symbolic Attributes in the Intention to Adopt Electric Vehicles. Transportation Research Part A, 48, 39-49.

[32] Erdem, C., Şentürk, İ. and Şimşek, T. (2010) Identifying the Factors Affecting the Willingness to Pay for Fuel-Efficient Vehicles in Turkey: A Case of Hybrids. Energy Policy, 38, 3038-3043. https://doi.org/10.1016/j.enpol.2010.01.043

[33] Daziano, R.A. and Chiew, E. (2012) Electric Vehicles Rising from the Dead: Data Needs for Forecasting Consumer Response toward Sustainable Energy Sources in Personal Transportation. Energy Policy, 51, 876-894.

https://doi.org/10.1016/j.enpol.2012.09.040

[34] Skerlos, S.J. and Winebrake, J.J. (2010) Targeting Plug-in Hybrid Electric Vehicle Policies to Increase Social Benefits. Energy Policy, 38, 705-708.

https://doi.org/10.1016/j.enpol.2009.11.014

[35] Mau, P., Eyzaguirre, J., Jaccard, M., Collins-Dodd, C. and Tiedemann, K. (2008) The "Neighbor Effect": Simulating Dynamics in Consumer Preferences for New Vehicle Technologies. Ecological Economics, 68, 504-516. https://doi.org/10.1016/j.ecolecon.2008.05.007

[36] Axsen, J. and Kurani, K.S. (2011) Interpersonal Influence in the Early Plug-in Hybrid Market: Observing Social Interactions with an Exploratory Multi-Method Approach. Transportation Research Part D, 16, 150-159. https://doi.org/10.1016/j.trd.2010.10.006

[37] Lee, K. (2008) Opportunities for Green Marketing: Young Consumers. Marketing Intelligence \& Planning, 26, 573-586. https://doi.org/10.1108/02634500810902839

[38] Edelstein, S. (2017) Electric Car Price Guide: Every 2017 All-Electric Car with Specs. Green Car Reports.

http://www.greencarreports.com/news/1080871_electric-car-price-guide-every-201 5-2016-plug-in-car-with-specs

[39] Delang, C.O. and Cheng, W.T. (2013) Hong Kong People's Attitudes towards Electric Cars. International Journal of Electric and Hybrid Vehicles, 5, 15. 
https://doi.org/10.1504/IJEHV.2013.053465

[40] Ernst, C.S., Hackbarth, A., Madlener, R., Lunz, B., Sauer, D.U. and Eckstein, L. (2011) Battery Sizing for Serial Plug-in Hybrid Electric Vehicles: A Model-Based Economic Analysis for Germany. Energy Policy, 39, 5871-5882. https://doi.org/10.1016/j.enpol.2011.06.038

[41] Al-Alawi, B.M. and Bradley, T.H. (2013) Total Cost of Ownership, Payback, and Consumer Preference Modeling of Plug-in Hybrid Electric Vehicles. Applied Energy, 103, 488-506.

[42] Wu, G., Inderbitzin, A. and Bening, C. (2015) Total Cost of Ownership of Electric Vehicles Compared to Conventional Vehicles: A Probabilistic Analysis and Projection across Market Segments. Energy Policy, 80, 196-214. https://doi.org/10.1016/j.enpol.2015.02.004

[43] Bockarjova, M. and Steg, L. (2014) Can Protection Motivation Theory Predict Pro-Environmental Behavior? Explaining the Adoption of Electric Vehicles in the Netherlands. Global Environmental Change, 28, 276-288.

[44] Liu, J. and Santos, G. (2015) The Plug-in Hybrid Electric Vehicles Potential for Urban Transport in China: The Role of Energy Sources and Utility Factors. International Journal of Sustainable Transportation, 9, 145-157.

[45] Schroeder, A. and Traber, T. (2012) The Economics of Fast Charging Infrastructure for Electric Vehicles. Energy Policy, 43, 136-144.

https://doi.org/10.1016/j.enpol.2011.12.041

[46] Liu, J. (2012) Electric Vehicle Charging Infrastructure Assignment and Power Grid Impacts Assessment in Beijing. Energy Policy, 51, 544-557.

https://doi.org/10.1016/j.enpol.2012.08.074

[47] Nayum, A., Klöckner, C.A. and Mehmetoglu, M. (2016) Comparison of Socio-Psychological Characteristics of Conventional and Battery Electric Car Buyers. Travel Behaviour and Society, 3, 8-20. https://doi.org/10.1016/j.tbs.2015.03.005

[48] Jensen, A.F., Cherchi, E. and Mabit, S.L. (2013) On the Stability of Preferences and Attitudes before and after Experiencing an Electric Vehicle. Transportation Research Part D: Transport and Environment, 25, 24-32. https://doi.org/10.1016/j.trd.2013.07.006

[49] Caperello, N.D. and Kurani, K.S. (2012) Households' Stories of Their Encounters with a Plug-In Hybrid Electric Vehicle. Environment and Behavior, 44, 493-508. https://doi.org/10.1177/0013916511402057

[50] Lane, B. and Potter, S. (2007) The Adoption of Cleaner Vehicles in the UK: Exploring the Consumer Attitude-Action Gap. Journal of Cleaner Production, 15, 1085 1092. https://doi.org/10.1016/j.jclepro.2006.05.026

[51] Hidrue, M.K., Parsons, G.R., Kempton, W. and Gardner, M.P. (2011) Willingness to Pay for Electric Vehicles and Their Attributes. Resource and Energy Economics, 33, 686-705. https://doi.org/10.1016/j.reseneeco.2011.02.002

[52] She, Z.-Y., Sun, Q., Ma, J.-J. and Xie, B.-C. (2017) What Are the Barriers to Widespread Adoption of Battery Electric Vehicles? A Survey of Public Perception in Tianjin, China. Transport Policy, 56, 29-40. https://doi.org/10.1016/j.tranpol.2017.03.001

[53] Razak, M.I.M., Yusof, A.M., Mashahadi, F., Alias, Z. and Othman, M.Z. (2014) Intention to Purchase Hybrid Cars in Malaysia an Overview. International Journal of Economics, Commerce and Management, 2, 1-13.

[54] Krupa, J.S., Rizzo, D.M., Eppstein, M.J., Brad Lanute, D., Gaalema, D.E., Lakkaraju, K. and Warrender, C.E. (2014) Analysis of a Consumer Survey on Plug-In Hybrid 
Electric Vehicles. Transportation Research Part A: Policy and Practice, 64, 14-31. https://doi.org/10.1016/j.tra.2014.02.019

[55] Wang, T., Wezel, F.C. and Forgues, B. (2016) Protecting Market Identity: When and How Do Organizations Respond to Consumers Devaluations? Academy of Management Journal, 59, 135-162.

[56] Hair, J., Black, W., Babin, B. and Anderson, R. (2010) Multivariate Data Analysis. 7th Edition, Prentice-Hall, Upper Saddle River.

[57] Fornell, C.G. and Larcker, D.F. (1981) Evaluating Structural Equation Models with Unobservable Variables and Measurement Error. Journal of Marketing Research, 18, 39-50. https://doi.org/10.1177/002224378101800104

[58] Lieven, T., Mühlmeier, S., Henkel, S. and Waller, J.F. (2011) Who Will Buy Electric Cars? An Empirical Study in Germany. Transportation Research Part D. Transport and Environment, 16, 236-243. https://doi.org/10.1016/j.trd.2010.12.001

[59] Thananusak, T., Rakthin, S., Tavewatanaphan, T. and Punnakitikashem, P. (2017) Factors Affecting the Intention to Buy Electric Vehicles: Empirical Evidence from Thailand. International Journal of Electric and Hybrid Vehicles, 9, 361-381. https://doi.org/10.1504/IJEHV.2017.089875

[60] Sierzchula, W., Bakker, S., Maat, K. and van Wee, B. (2014) The Influence of Financial Incentives and Other Socio-Economic Factors on Electric Vehicle Adoption. Energy Policy, 68, 183-194. https://doi.org/10.1016/j.enpol.2014.01.043

[61] Rezvani, Z., Jansson, J. and Bodin, J. (2015) Advances in Consumer Electric Vehicle Adoption Research: A Review and Research Agenda. Transportation Research Part D: Transport and Environment, 34, 122-136.

https://doi.org/10.1016/j.trd.2014.10.010 